\title{
THE ANNUAL MEETING
}

The annual meeting of the Saskatchewan Natural History Society will be held at the Provincial Museum, Regina, on Friday, October 26. Registration will be from 9.30 to 10 a.m.

Plan to take a day or two off and attend this meeting. Those who came last year were enthusiastic about the success of the three sessions.

The Executive is arranging a full and interesting program. Illustrated and other lectures, as well as special exhibits, will be the chief feature of the sessions, morning, afternoon and evening. The business meeting and election of officers will take place from 2 to 4.30 in the afternoon.

Mark the date on your calendar - Friday, October 26.

\section{Are Your Dues in Arrears?}

It is very important that all 1951 subscription fees be paid as soon as possible. These fees were due and payable on January 1st of this year.

The Society is in a critical period financially. Increased costs of supplies, publication and postage are straining our funds to the limit. The total cost of each issue is now in the neighbourhood of $\$ 175$ and it may soon reach $\$ 200$.

Our membership goal at the present time is 1000 . We still have less than 600 regular members. In addition, 200 copies of each issue are distributed to employees of the Department of Natural Rescurces for circulation, by the director of the provincial museum. These have been contracted for at a reduced price. It was with great regret that we were compelled to drop 40 names from our mailing list last year, whose arrears dated back to December 31, 1949.

We appeal to members to endeavour to increase our circulation and to retain our present membership.

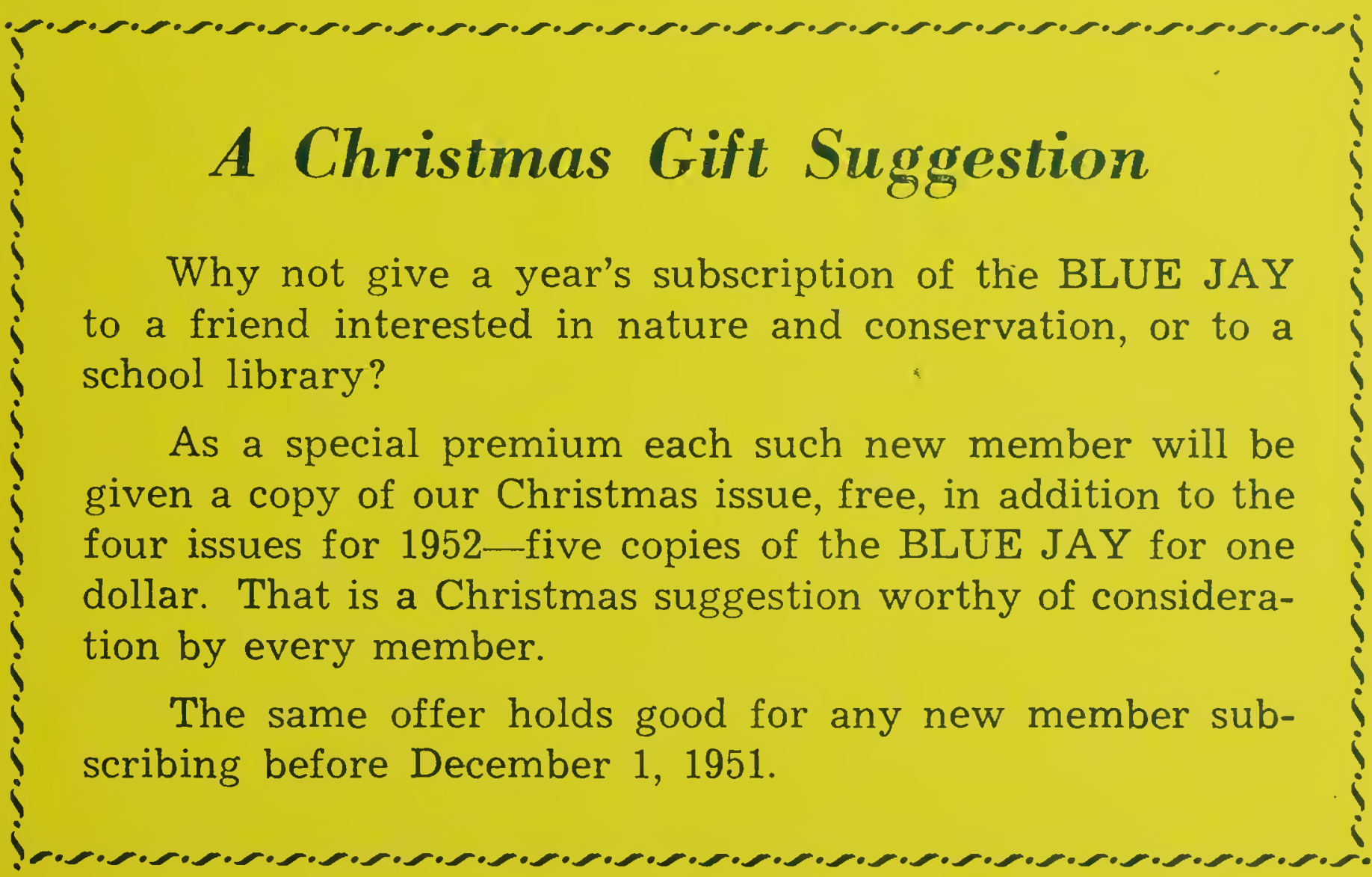

